\title{
Niepamięć operacyjna \\ Dyskursy pamięci, zapomnienia i post-pamięci w rozrywce interaktywnej
}

\section{Volatile Memory. Discourses of Memory, Forgetting, and Post-memory in Interactive Entertainment}

\begin{abstract}
My aim in this article is to analyse tools that are used to improve the processes of memory in video games. The discussion will open with a look at the methods used by game developers to reconcile the antithetic trends of discourse: the structural narrative and the interactive nature of the medium. Consequently, narrative clichés in the form of amnesia as well as innovative techniques that use tools characteristic of interactive entertainment will be analysed. The main thesis of this analysis is that in comparison to traditional narratives the processes of memory loss, forgetting and consequent emergence of post-memory, play a more important role in video games. This way of reinterpreting memories will largely shape our perception of the concept of temporality in interactive entertainment. It will require a departure from the traditional perspective of time and a transition to the interpretation of time from the perspective of Bergson and Deleuze.
\end{abstract}

Keywords; memory, post-memory, interactive entertainment

Pamięć w rozrywce interaktywnej jest zasobem ograniczonym. I nie chodzi tu jedynie o wydajność sprzętu, choć i to ograniczenie odgrywa w tym dyskursie ważną rolę. Przede wszystkim, pamięć w grach wideo musi funkcjonować na wąskiej granicy pomiędzy tym, co narracyjnie logiczne, a tym, co stanowi raison d'être tego typu rozrywki - interakcją gracza w świat przedstawiony. Interakcja $\mathrm{z}$ natury jest dynamiczna, pamięć - przynajmniej w jej tradycyjnym pojęciu statyczna (pamięć jako zdolność do powtarzania). Twórcy gier, szczególnie tych, w których narracja osadzona jest $w$ rozbudowanym świecie przedstawionym, stają przed trudnym zadaniem. Nie wykorzystać tego zasobu, to skonstruować bohatera pozbawionego pamięci, oderwanego od rzeczywistości, w której jakoby funkcjonował do momentu pojawienia się gracza. Z kolei eksploatować zasoby

1. Zob. Andrzej Szpociński, Pamięć przeszłości a formy przekazu, w: Pamięćw dobie Internetu, red. Olga Kołakowska, Rafał Krajzewicz, Marcin Trepczyński, Warszawa 2011. 
pamięci w nadmiarze, to zmienić grę w prezentację wydarzeń, które były, zamiast tych, na które gracz może mieć wpływ. Posługiwanie się zasobami pamięci staje się więc często wyznacznikiem umiejętności projektowania światów rozrywki interaktywnej.

W niniejszej pracy podejmuję się analizy narzędzi, które wykorzystywane są, by usprawnić procesy pamięci w grach wideo. Dyskusję otworzy przyjrzenie się metodom stosowanym przez twórców gier, by pogodzić antytetyczne nurty dyskursu. Analizie poddane zostaną zarówno klisze narracyjne w postaci tropów amnezji, jak i nowatorskie techniki, które wykorzystują narzędzia charakterystyczne dla rozrywki interaktywnej.

W drugiej części przedstawione zostaną perspektywy na specyficzną rolę pamięci nie tylko w kwestiach narracyjnych, lecz także w aspektach gier jako medium. Tutaj przede wszystkim analizowane będzie wyjście poza tradycyjne postrzeganie pamięci, przejście od bazy danych do interaktywnego procesu, prowadzące do konstrukcji nowych form i mechanizmów narracyjnych. Badane będą takie zjawiska jak tworzenie się pamięci zbiorowej i pamięci transaktywnej w subkulturach rozrywki interaktywnej.

Jednym z podstawowych założeń tej analizy będzie teza, że w porównaniu do narracji tradycyjnych, w grach wideo znacznie ważniejszą rolę odgrywają procesy niepamięci, zapomnienia i postpamięci, rozumianej jako wypadkowa poprzednich pojęć. Taki sposób reinterpretacji wspomnień będzie w dużym stopniu kształtował naszą percepcję pojęcia temporalności w rozrywce interaktywnej. Będzie wymagał odejścia od tradycyjnej perspektywy czasu jako „chronologicznej sukcesji momentów świadomości, [...] nieodwracalnego i liniowego postępu stanów psychologicznych" ${ }^{\text {i }}$ przejście do interpretacji czasu z perspektywy Bergsona i Deleuze'a ${ }^{3}$.

\section{Pamięć, interakcja, kontrola}

Wspomniany we wstępie problem z zasobami pamięci, tak szczególny dla rozrywki interaktywnej, jest spowodowany swego rodzaju schizofrenią medium gier komputerowych. Co ciekawe, nie jest to stan inherentny dla tego typu rozrywki, ale raczej świadomy wybór twórców gier, którzy w pogoni za większym udziałem w przestrzeni mentalnej publiczności sami siebie skazali na to rozdwojenie jaźni. Można nawet pokusić się o wysunięcie tezy, że w przeciwieństwie do zwrotu

2. Alia Al-Saji, The Memory of Another Past: Bergson, Deleuze and a New Theory of Time, „Continental Philosophy Review”, 2004, 37(2), s. 204 (przeł. T.G.).

3. Gilles Deleuze, Bergsonizm, przeł. Piotr Mrówczyński, Wydawnictwo KR, Warszawa 1999. 
cyfrowego ${ }^{4}$, który dostrzegalny jest $\mathrm{w}$ dziedzinach humanistyki, rozrywka interaktywna doświadczyła zwrotu narratywistycznego ${ }^{5}$.

Nie jest to zjawisko nowe, ale w obecnych czasach z całą pewnością stało się bardziej dostrzegalne. O ile w przeszłości narracja (w rozumieniu tradycyjnym) w grach stanowiła raczej tło do rozrywki, o tyle w dzisiejszych czasach wielu twórców i krytyków uważa ją za ważny element oferowanego doświadczenia. Jak sugeruje Rune Klevjer, czasem rola narracji jest „pragmatyczna” i funkcjonuje ona jedynie jako „system progresji (z wyraźnym celem), struktura nagradzania i mechanizm regulujący wprowadzanie nowych elementów" ${ }^{\text {. }}$ Nie zmienia to jednak faktu, że w grach coraz większy nacisk kładziony jest na stworzenie „doświadczenia narracyjnego"” . W tym przypadku mniej liczy się cel, a większe znaczenie ma metoda.

Dobrym przykładem momentu liminalnego były narodziny gier RPG. Rubikonem stało się tu przejście od gier, gdzie nacisk kładziony był głównie na mechanikę (symulacje bitewne i wojenne wywodzące się od XIX-wiecznego Kriegsspiel), do gier, gdzie graczom, jak to określiła Shannon Appelcline, „oferuje się możliwość interakcji z fantastycznymi światami w bardziej intymny sposób”. W 1971 roku, kiedy Gary Gygax stworzył system bitewny Chainmail (Guidon Games, 1971), jedną z najwcześniejszych jego modyfikacji był napisany przez Dave'a Arnesona Blackmoore (Tactical Studies Rules, 1971) - pierwsza gra typu RPG, gdzie ważnym elementem rozgrywki było interaktywne tworzenie narracji w tradycyjnym znaczeniu tego słowa. Na podstawie modułu Arnesona powstał system Dungeons \& Dragons (Tactical Studies Rules, 1974), który szybko zyskał popularność znacznie przewyższającą gry wojenne, które były pierwowzoremtego typu rozrywki. Warto tu podkreślić za Edwardsem, iż

4. Andrzej Radomski, Radosław Bomba, red., Zwrot cyfrowy w humanistyce, E-naukowiec, Lublin 2013.

5. Aczkolwiek nie można zapominać o zwrocie narratywistycznym w humanistyce, o którym pisze m.in. Anna Burzyńska, Kariera narracji. O zwrocie narratywistycznym w humanistyce, w: Narracja i tożsamość (II). Antropologiczne problemy literatury, red. Włodzimierz Bolecki, Ryszard Nycz, Wydawnictwo IBL PAN, Warszawa 2004. Postmodernizm najwyraźniej charakteryzuje się dużą liczbą zwrotów.

6. Rune Klevjer, In Defense of Cutscenes, Department of Media Studies / InterMedia, University of Bergen <http://citeseerx.ist.psu.edu/viewdoc/download?doi=10.1.1.190.1300\&rep=rep1\&type$=$ pdf $>$ (1.04.2019), (przeł. T.G.).

7. Noah Wardrip-Fruin, Pat Harrigan, ted., First Person: New Media as Story, Performance, and Game, MIT Press, Cambridge 2004.

8. Shannon Appelcline, Designers \& Dragons. The 70s, Evil Hat Productions, Silver Spring 2014, s. 16 (przeł. T.G.). 
sformułowanie jakoby Dungeons \& Dragons „wynalazło role-playing” jest bezwzględnie błędne. D\&D było raczej wydawniczym epifenomenem, który dostarczył surowego materiału, a nie samej procedury. Dostarczył pierwszych oficjalnych tekstów role-playingu, ale te teksty same w sobie nie były w żaden sposób odkrywcze ${ }^{9}$.

To stwierdzenie jest ważne z podstawowego dla tej dyskusji powodu - już na tak wczesnym etapie rozwoju łatwo dostrzec, że narracja w grach nie była wyłącznie rezultatem wewnętrznej potrzeby twórców, by opowiadać historie, ale w dużej mierze stała się wypadkową mechanizmów rynku.

Dość łatwo jest odpowiedzieć na pytanie, dlaczego zwrot narratywistyczny miał miejsce - przynajmniej w szerokiej perspektywie. Wybór słowa „intymny” u Appelcline’a, by określić relacje ze światem gry, wydaje się wskazywać powód. Narracja, w porównaniu do abstrakcyjnej mechaniki gry, jest dla zwykłego odbiorcy bardziej wisceralna, rozpoznawalna, przyswajalna. Narracja się sprzedaje, narracją sprzedaje się mechaniki gier. Przykład tego zjawiska opisuje Marie-Laure Ryan, analizując techniki wykorzystywane przez wydawców gier w latach osiemdziesiątych XX wieku. Ograniczone możliwości techniczne nie pozwalały na rozbudowane narracje w grach, ale "obietnice” narracyjne były realizowane poza medium - kolorowe pudełka z zarysem historii i wizualizacjami świata przedstawionego. Jak stwierdza Ryan, „poprzez techniki reklamy, projektanci odwoływali się do wyobraźni gracza, która miała dostarczyć narracji niemożliwych do zaimplementowania w samej grze"10. Wraz z rozwojem możliwości technicznych narracje zaczęły wędrówkę z pudełek do wnętrza gier. I tu pojawił się problem, u którego podstawy leży, jak to często bywa, semantyka.

\section{Immersja a obecność}

Jednym z najbardziej popularnych epitetów odnoszących się do medium rozrywki interaktywnej jest immersyjność. Sama idea immersyjności była już wielokrotnie poddawana analizie ${ }^{11}$, jednakże nadal istnieje znaczący rozdźwięk

9. Ron Edwards, A Hard Look at Dungeons and Dragons <http://www.indie-rpgs.com/articles/20/>, cyt. za: René Reinhold Schallegger, The Postmodern Joy of Role-Playing Games: Agency, Ritual and Meaning in the Medium (Studies in Gaming), McFarland \& Company, Inc., Jefferson, NC, 2018), s. 113 (przeł. T.G.).

10. Marie-Laure Ryan, Avatars of Story, University of Minnesota Press, Minneapolis 2006, s. 21 (przeł. T.G.).

11. Penelope Sweetser, Peta Wyeth, Game Flow: A Model for Evaluating Player Enjoyment in Games, „ACM Computers in Entertainment”, vol. 3, no. 3, July 2005, Article 3A; David Weibel, Bartholomäus Wissmath, Immersion in Computer Games: The Role of Spatial Presence and Flow, „International Journal of Computer Games Technology”, vol. 3, January 2011; Georgios Christou, The Interplay between Immersion and Appeal in Video Games, „Computers in Human Behavior” 
pomiędzy tym, jak interpretowana jest w opracowaniach naukowych i w języku potocznym. Alison McMahan podkreśla ten problem, zauważając, iż: „immersyjność stała się nadmiernie mglistą, kumulatywną koncepcją"12. Za przykład może tu posłużyć choćby dyskusja nad immersją przedstawiona w artykule Krystyny Januszkiewicz. Autorka zaczyna od stwierdzenia: „immersja jest przestrzenią; iluzja to efekt zastosowanej techniki przestawienia, immersja to zaangażowany odbiór, w którym dzieło ogarnia odbiorcę, oddziałując w pełni na jego władze poznawcze"13. W tej interpretacji zjawiska, zaangażowanie wydaje się jedynie ograniczać do zmiany perspektywy: „[c]złowiek zawsze wytwarzał technologie wizualnej symulacji i opierał na nich swoje doświadczanie rzeczywistości. Reprezentacje te pośredniczyły pomiędzy nim a światem, umożliwiając widzenie i rozpoznawanie tego, co nazwano realnością"14. Taka interpretacja jest oczywiście słuszna, ale przedstawia zjawisko głównie jako doświadczenie raczej pasywne. Pomimo iż Januszkiewicz w dalszej części swojej analizy zwraca uwagę na ważny aspekt interaktywności: „zjawisko immersji zachodzi tu najczęściej w kontekście elektronicznej sztuki interaktywnej"15, wydaje się, że w większości omawianych przypadków publiczność zredukowana jest do odbiorcy wrażeń, a interaktywność $\mathrm{z}$ medium pozostaje ograniczona.

Ponadto pojęcia immersyjności i interakcji zdają się funkcjonować nie tyle jako zamienniki, ale raczej nierozłączny tandem. Tej perspektywie można przeciwstawić spostrzeżenie McMahan, która stwierdza, iż: „immersja oznacza, że gracz zanurza się w świecie gry (poziom diegetyczny), ale odnosi się również do zamiłowania gracza do gry jako mechaniki i strategii grania (poziom niediegetyczny). Wydaje się oczywiste, że jeśli dyskutujemy o immersji w grach wideo na poziomie diegetycznym i immersji na poziomie niediegetycznym, to mówimy o dwóch różnych zjawiskach, prawdopodobnie reprezentujących sprzeczne zestawy konwencji estetycznych"16. McMahan wydaje się traktować właśnie interakcję jako jeden z elementów tych sprzecznych zestawów konwencji estetycznych. Widać to choćby, gdy wyszczególnia warunki, które wspomagają doświadczenie

32(C), March 2014; Georgios Christou, The Interplay between Immersion and Appeal in Video Games, „Computers in Human Behavior” 32(C), March 2014.

12. Alison McMahan, Immersion, Engagement, and Presence. A Method for Analyzing 3-D Video Games, w: The Video Game Theory Reader, red. Mark J.P. Wolf, Bernard Perron, Routledge, Abingdon 2013, s. 67 (przeł. T.G.).

13. Krystyna Januszkiewicz, Powierzchnia jako nowe uwarunkowanie kulturowe. Środowiska immersyjne i projektowanie przeżyć, „AV”, 2/2014, str. 48. <https://www.academia.edu/14842738/K._Januszkiewicz_\%C5\%9Arodowiska_immersyjne_i_projektowanie_prze\%C5\%BCy\%C4\%87_AV_2_2014> (01.04.2019)

14. Januszkiewicz, Powierzchnia..., s. 48.

15. Januszkiewicz, Powierzchnia..., s. 49.

16. McMahan, Immersion..., s. 68 (przeł. T.G.). 
immersyjności: „(1) oczekiwania użytkownika wobec środowiska gry muszą współgrać z konwencjami środowiskowymi; (2) działania użytkownika muszą mieć nietrywialny wpływ na środowisko; oraz (3) konwencje świata muszą być spójne, nawet jeśli nie pasują do »realu«"17. Punkt drugi na tej liście odnosi się do interaktywności, jednakże immersyjność może być osiągnięta z jej pominięciem, o ile odpowiednio przedstawione zostaną pozostałe elementy - wszakże dokładnie tak funkcjonuje immersyjność mediów nieinteraktywnych, takich jak tradycyjne kino czy książka.

Z kolei by odpowiedzieć, dlaczego tak interpretowana interaktywność i tradycyjne pojęcie immersyjności mogą być niekompatybilne, warto odnieść się do uwag Boltera i Grusina dotyczących problematyki reprezentacji rzeczywistości wirtualnej. Autorzy zauważają: „aby stworzyć poczucie obecności, wirtualna rzeczywistość powinna być jak najbliżej naszego codziennego doświadczenia wizualnego. Jego przestrzeń graficzna powinna [...] wypełniać pole widzenia widza bez załamań. Ale dzisiejsza technologia wciąż zawiera wiele załamań: mała szybkość klatek, postrzępiona grafika, jaskrawe kolory, mdłe oświetlenie i awarie systemu"18. O ile w przypadku wpływu na zmysły technologia często poszła do przodu (realizując punkt 1 i 3 McMahan), o tyle najbardziej znaczącym „załamaniem” nadal pozostaje brak pełnej interaktywności z medium (punkt 2 McMahan). Znikoma interaktywność, zamiast wzmacniać iluzję rzeczywistości, podkreśla jej niedoskonałość.

McMahan wprowadza więc bardziej precyzyjne niż immersyjność pojęcie obecności, które charakteryzuje na podstawie badań Lombarda i Ditton. Metodami na zwiększenie poczucia obecności są następujące procesy:

\begin{abstract}
jakość interakcji społecznych, realizm środowiska (grafika, dźwięk itp.), efektu „przeniesienia”, czyli stopień immersyjności generowany przez interfejs, umożliwienie użytkownikowi znaczącego oddziaływania na środowisko i skutki społeczne tego oddziaływania oraz fakt traktowania programu komputerowego przez użytkownika jako inteligentnej, społecznej jednostki ${ }^{19}$.
\end{abstract}

Konstruowanie immersyjności z wykorzystaniem powyższych metod jest konieczne, by gry zachowały podstawową cechę odróżniającą ją od innych mediów - interaktywność.

Problemem w naszym przypadku jest fakt, że tworzenie rozbudowanej struktury narracyjnej, która sugeruje istnienie głębokiej pamięci, bywa niekompaty-

17. McMahan, Immersion..., s. 69 (przeł. T.G.).

18. Jay David Bolter, Richard Grusin, Remediation: Understanding New Media, MIT Press, Cambridge 2000, s. 22 (przeł. T.G.).

19. McMahan, Immersion..., s. 72 (przeł. T.G.). 
bilne z niektórymi metodami wymienionymi powyżej. Dla przykładu, często wykorzystywane wprowadzenie w postaci filmu krótkometrażowego tworzy immersję zmysłową (oprawa audiowizualna jak „realizm środowiska”) oraz oddziałuje na zaangażowanie w narrację (związek emocjonalny z przedstawionymi postaciami jako ,jakość interakcji społecznych”). W obu jednak przypadkach jest to doświadczenie pasywne, w niczym nieróżniące się od technik wykorzystanych $\mathrm{w}$ innych mediach. Ten biegun spektrum oddaje twórcy gry pełną kontrolę nad narracją, ale obecność gracza sprowadza się do obecności biernego widza, a nie uczestnika rozgrywki. Pojawia się tu pytanie, czy ograniczenie głównego elementu odróżniającego gry od innych mediów jest zabiegiem słusznym.

Odpowiedź możemy znaleźć, analizując reakcje użytkowników na gry produkowane przez studio Telltale Games. Mimo różnorakich światów przedstawionych i franczyz fabularnych wykorzystanych $w$ grach tej firmy ${ }^{20}$ podstawową mechaniką rozgrywki jest poruszanie się wzdłuż dość ograniczonej linii narracyjnej. Wybory, których gracz dokonuje (pamięć narracyjna gry), mają najczęściej niewielki wpływ na historię zaprojektowaną przez autorów. Ograniczenie innych mechanik typowych dla gier przygodowych sprawia zaś, że interakcja sprowadza się głównie do wyborów niewiele znaczących opcji dialogowych i trywialnych zręcznościowych przerywników (QTE). W efektcie gracze, którzy najwidoczniej oczekiwali czegoś więcej niż tylko odegranie z góry ustalonej ścieżki - i którym, co gorsza, marketing Telltale Games obiecał coś więcej, poczuli się zawiedzeni. Recenzenci ujęli to w dość dobitny sposób:

The Walking Dead okazał się dla mnie pod tym względem jednym wielkim szwindlem ${ }^{21}$.

Fani zaczęli masowo zauważać, że ich wybory nie mają sensu. Poczuli, że są oszukiwani (zwłaszcza przez krzykliwe kampanie marketingowe traktujące o ważnych decyzjach moralnych ${ }^{22}$.

Podejmowanie decyzji w butach Mrocznego Rycerza już w punkcie wyjścia jest spalone. Jako fan komiksów, od razu wiedziałem, jak postąpiłby Bruce Wayne. Szukanie innych dróg do celu i innych możliwości wydaje się bezzasadne. Poza tym alternatyw tak

20. By wymienić najbardziej rozpoznawalne: Back to the Future: The Game (Telltale Games, 2010), Jurassic Park: The Game (Telltale Games, 2011), Law \& Order: Legacies (Telltale Games, 2011), The Walking Dead (Telltale Games, 2012), Minecraft: Story Mode (Telltale Games, 2015), Game of Thrones (Telltale Games, 2014), Batman: The Telltale Series (Telltale Games, 2014).

21. Squaresofter, Epitafium dla Telltale Games, „Gameplay.pl” <https:/gameplay.pl/news. asp?ID=111390> (1.04.2019).

22. Ewelina Stój, Upadek studia Telltale Games, czyli lepszy zombiak w garści, niż Batman na dachu, „Komputer Świat” <https://www.komputerswiat.pl/gamezilla/artykuly/upadek-studia-telltale-games-czyli-lepszy-zombiak-w-garsci-niz-batman-na-dachu/4qtbl0v> (1.04.2019). 
naprawdę nie ma, a w Batman: The Telltale Games Series wszystkie ścieżki prowadzą do tych samych zakończeńn ${ }^{23}$.

Z powyższych cytatów można wywnioskować, że gracze świadomie wybierają medium gier, ponieważ mogą w nich być czymś więcej niż tylko biernym widzem. Drugim biegunem spektrum interaktywności jest oczywiście przekazanie całkowitej kontroli w ręce graczy. Tutaj jednak oczywiście pojawia się dylemat - w jaki sposób jednocześnie dostarczyć spójnego doświadczenia narracji (skonstruować głęboką pamięć) i dać możliwość wpływu na nią? Jak zespolić pamięć postaci narracyjnej z niepamięcią gracza odgrywającego tę postać narracyjną? W następnej części podejmę się analizy metod, przy użyciu których twórcy gier starają się odnaleźć złoty środek, stający się pomostem łączącym zamysł autorski i możliwość współudziału w narracji przez graczy.

\section{Amnezja - niepamięć operacyjna}

Najprostszą i przez to najczęściej stosowaną metodą na pogodzenie dysonansu pomiędzy wiedzą bohatera gry a graczem jest wymazanie pamięci tego pierwszego. Tego typu konwencja była stosowana już na początku rozwoju gier kładących nacisk na rozbudowaną narrację i w dalszym ciągu jest wykorzystywana przez wielu twórców. Dla przykładu w grze o wiele mówiącym tytule Flashback: The Quest for Identity (Delphine Software International, 1992), bohater odzyskuje przytomność po katastrofie swego pojazdu, który został zestrzelony przez nieznanych napastników. Przewodnikiem staje się tutaj nagranie z przeszłości, w którym nasz bohater przed utratą pamięci informuje nas, co mamy dalej zrobić. Pierwszym celem podróży staje się więc przywrócenie utraconych wspomnień. Z kolei w Star Wars: Knights of the Old Republic (BioWare, 2003), o naszej amnezji zostajemy poinformowani w późniejszym etapie rozrywki, gdy okazuje się, że nie jesteśmy jedynie awatarem gracza, ale postacią należącą do świata przedstawionego narracji. W The Witcher (CD Projekt RED, 2007) amnezja jest interesująco selektywna. Główny bohater pamięta niektóre wydarzenia ze swojej przeszłości, ale utracił zdolności charakterystyczne wiedźminom.

Powyższe gry to jedynie kilka przykładów, gdzie amnezja jest wykorzystana jako narzędzie narracyjne. Na MobyGames, internetowej bazie danych dotyczącej rozrywki interaktywnej, można znaleźć listę ponad stu gier, w których amnezja odgrywa znaczącą rolę. O niesłabnącej popularności tej techniki dobrze świadczą daty wydania poszczególnych przykładów - najwcześniejszą grą na liście jest

23. Szymon Radzewicz, Przygodowy Batman ma wielka, deklasująca go wade - recenzja Spider's Web, „Spider's Web” <https://www.spidersweb.pl/2016/08/batman-the-telltale-games-series.html> (1.04.2019). 
Cyborg (Brøderbund Software, 1981), najpóźniejszą Tasokare Hotel (SEEC inc., 2019). Znaleźć tu można zarówno RPG i gry przygodowe, produkty dużych producentów, jak i gry niezależne. Należy zwrócić uwagę, że uwzględnione na liście zostały tylko przypadki, gdzie głównym punktem fabuły jest próba odzyskania utraconych wspomnień. Lista nie uwzględnia gier, gdzie „postać budzi się bez wspomnień/pamięci, jednak ten stan nie jest wykorzystany w fabule gry"24.

W omówionych przykładach przyczyny fabularne amnezji są oczywiście różne, od magicznych klątw, przez naukowe i pseudonaukowe metody technologiczne, aż do zwyczajowego uderzenia w głowę. W wielu przykładach wspomnianych powyżej niepamięć jest traktowana narzędziowo, zostaje całkowicie podporządkowana schematowi fabularnemu utworu. Mimo obiecującego tytułu, we Flashback: The Quest for Identity niepamięć jest jedynie pomniejszą przeszkodą na drodze do celu, którym bynajmniej nie okazuje się egzegeza jednostkowości, ale uratowanie świata przed kosmicznymi najeźdźcami. Bohater sterowany przez gracza traci i odzyskuje pamięć mechanicznie i gdy tylko amnestyczny stan przestaje być narracyjnie potrzebny, znika, nie pozostawiając żadnego śladu. Podobną sytuację mamy w Star Wars: Knights of the Old Republic, gdzie znów niepamięć jest jedynie kurtyną, która w stosownym momencie unosi się, by odsłonić kolejne akty przygody. The Witcher jest przykładem ciekawszym, bo tutaj bardziej uwypuklona została wielorakość mechanizmów kształtujących narrację w grach wideo. Problemem, z jakim poradzić musieli sobie twórcy, był nie tyle brak wiedzy graczy odnośnie do świata przedstawionego, ale raczej jej nadmiar. Postać Geralta była już precyzyjnie określona dzięki rozpoznawalnej franczyzie. Geralt był doświadczonym łowcą potworów i znakomitym wojownikiem. Ten element jednak nie pasował do podstawowych założeń projektu RPG, gdzie postać sterowana przez gracza zaczyna jako słabeusz, by dopiero w procesie gry osiągnąć mistrzostwo. W tym przypadku więc amnezja również została potraktowana narzędziowo, ale zamiast wyłącznie wspomagać strukturę narracyjną, miała za cel wyjaśnić mechanizmy rozgrywki.

We wszystkich jednak przypadkach pamięć bohatera zostaje sprowadzona do punktu zero, gdzie na początku gry znajduje się również pamięć gracza. $\mathrm{Z}$ początku wydawać by się mogło, że rola amnezji odnosi się tu do tworzenia warunków koniecznych do powstania tekstu ergodycznego ${ }^{25}$, wspomnianego raison d'être gier komputerowych jako odrębnego medium. Nietrywialnym wysiłkiem i elementem ekstranoematycznym byłaby tu jakoby konieczność odzyskania pamięci, „odbudowania” utraconych wspomnień (co wydaje się sugerować

24. Autor nieznany, Theme: Amnesia, w „Moby Games” <https://www.mobygames.com/ game-group/theme-amnesia/offset,0/so,1d/> (1.04.2019), (przeł. T.G.).

25. Espen J. Aarseth, Cybertext: Perspectives on Ergodic Literature, JHU Press, Baltimore 1997. 
podtytuł Flashback: The Quest for Identity). Jednakże w omawianych tytułach nie mamy do czynienia z konstrukcją, bądź rekonstrukcją (dekonstrukcją?), lecz z odtworzeniem schematów z przeszłości, których kształt i natura leży poza kontrolą gracza. Kontinuum czasu w tym przypadku nie zostaje w żaden sposób zmienione, a jedynie elementy je stanowiące ulegają pewnemu przetasowaniu formalistyczny zabieg bazujący na rozróżnieniu pomiędzy fabułą a sjużetem ${ }^{26}$.

Odzyskiwanie pamięci jest tu częściej procesem konstruowania teraźniejszości niż rekonstrukcją przeszłości. Wszystko to odwołuje się do tradycyjnego postrzegania czasu jako liniowej osi z wyraźnym punktem początku i końca. Ruch na tej osi odbywa się w jednym kierunku, przeszłość, pamięć, wspomnienia odkrywane są w trybie teraźniejszym i liczą się tylko w odniesieniu do tu i teraz. Gracz doświadcza świat gry jako zbioru chronologicznych momentów akcji i sam jest determinowany przez głównie zewnętrzne bodźce. Wybory i konsekwencje są mechaniczną reakcją na impuls najbliższego środowiska. Ten sposób budowania opowieści tworzy w wielu grach typ pamięci, który można określić jako „pamięć operacyjną", ograniczoną do przyczynowo-skutkowych związków, pozbawioną szerszych połączeń charakteryzujących Deleuzjańskie kłącze. Taka metodologia nie jest w żadnym wypadku niewskazana, jednakże bazuje ona na tradycyjnych metodach narracji charakterystycznych dla klasycznych nurtów literatury czy kina. A tutaj wszakże narracja funkcjonuje w medium rozrywki interaktywnej, które rządzi się po części innymi prawami.

By lepiej zrozumieć te prawa, warto w tym momencie wrócić do omówionej poprzednio różnicy pomiędzy obecnością a immersją i spróbować powiązać te pojęcia z percepcją czasu. Punktem wyjścia będzie stwierdzenie Clive’a Fencotta, który zauważył, że: „obecność jest stanem psychicznym, dlatego jest bezpośrednim wynikiem postrzegania, raczej niż odczuciem. Innymi słowy, konstrukcje mentalne, które ludzie budują na bazie bodźców, są ważniejsze niż same bodź$\mathrm{ce}^{\text {"27. }}$. Na podstawie tego założenia można wysunąć tezę dotyczącą relacji obecności a czasu - poszczególne wydarzenia stanowiące opowieść są mniej istotne w procesie tworzenia poczucia obecności niż sposób prezentacji tych wydarzeń, akt wspomagania specyficznych konstruktów mentalnych. Pamięć nie jest tak ważna, jak niepamięć. To założenie jest bliskie Deleuzjańskiej koncepcji czasu-kłącza, która podkreśla nie tyle istotę poszczególnych wydarzeń, ile sieć połączeń istniejącą między nimi.

26. Maria Pramaggiore, Tom Wallis, Film: A Critical Introduction, Laurence King Publishing, London 2005.

27. Clive Fencott, Presence and the Content of Virtual Environments $<$ http://web.onyxnet. co.uk/Fencott-onyxnet.co.uk/pres99/pres99.htm> (1.04.2019), (przeł. T.G.). 
W przykładach amnezji omówionych powyżej główny nacisk kładziony jest na momentalny odbiór bodźca. Niepamięć stwarza natychmiastową potrzebę wypełnienia, jest motorem akcji, ale napędza ją w sposób mechaniczny - gracz jest niesiony z prądem niepamięci do ściśle określonego celu. Można się nawet posunąć do stwierdzenia, iż w tym świecie błyskawicznych, liniowych połączeń gracz nie pamięta faktu, że ma amnezję. W tym przypadku czas jest wyłącznie wędrówką jedynego ruchomego obiektu (gracz-awatar-postać) we wszechświecie stałych elementów. Ta perspektywa nie pozwala na zaistnienie Bergsonowskiego czasu psychologicznego: „trwania i wyczekiwania, doświadczonego jako antycypacja i niecierpliwość, które pociągają za sobą pamięć. Nie można go sobie wyobrazić bez pamięci" ${ }^{28}$. Tutaj nie ma wspomnień, pamięć nie istnieje. Jest tylko płytki teraźniejszy bodziec symulujący przeszłość, pozorujący głębię czasu przedstawionego.

Istnieją jednak przykłady gier, gdzie amnezja i problem pamięci zyskuje dodatkową głębię i staje się czymś więcej niż tylko opóźnionym spełnieniem paradygmatów narracji. W Planescape: Torment (Black Isle Studios, 1999), gracz wciela się w postać Bezimiennego, który stracił nie tylko pamięć, lecz także śmiertelność. Z początku wydawać by się mogło, że zarówno procesy pamięci, niepamięci, jak i sam schemat narracyjny przedstawiony w grze, nie różnią się znacznie od innych tekstów, gdzie wykorzystano trop amnezji. Tutaj również podróżujemy przez świat gry, próbując zrekonstruować naszą przeszłość i odnaleźć zaginione wspomnienia. Tym, co jednak wyróżnia Planescape: Torment jests metodologia zapisu i odczytu pamięci, a także swego rodzaju mentalny konstrukt, jaki staje się wypadkową tego procesu.

Po pierwsze, pamięć w grze jest w dużym stopniu oparta na cielesności Bezimiennego, stając się nie tylko abstrakcyjnym czynnikiem narracji Planescape: Torment, lecz także rzeczywistym elementem świata przedstawionego. Już na samym początku rozgrywki doświadczamy tego procesu. W pierwszym dialogu, jaki prowadzimy z napotkaną postacią, zostajemy poinformowani o fakcie, że całe nasze ciało jest pokryte tatuażami - zapisem wspomnień, uwag i instrukcji, które pozostawiliśmy sami sobie właśnie na wypadek amnezji. W dalszych etapach gry, wiele osiągnięć (ukończone zadania, poznani bohaterowie niezależni) daje nam możliwość kontynuacji tego typu zapisu wspomnień poprzez pozyskiwanie kolejnych tatuaży.

Sama cielesność w Planescape: Torment jest zaprezentowana jako swego rodzaju bricolage, zbiór modyfikowalnych elementów, bardziej niż skończona całość. Kolejne artefakty ciała, które odnajdujemy w czasie naszej podróży, stają

28. Pete A. Y. Gunter, Andrew C. Papanicolaou, Bergson and Modern Thought, Routledge, Abingdon 2016, s. 81 (przeł. T.G.). 
się elementami układanki pozwalającej odbudować naszą pamięć - lub przynajmniej jedną z wersji naszej pamięci. Jednym z ciekawszych, aczkolwiek dość makabrycznych przykładów jest spora kolekcja oczu, które Bezimienny może zebrać w czasie swojej wędrówki. Bohater może zdecydować się na wymianę swojego naturalnego narządu na tak egzotyczne artefakty, jak Czarcie Oko Kalem'Darra czy Kalejdoskopowe Oko. Każda podmiana modyfikuje nasze zdolności, w dość dosłowny sposób zmieniając percepcję świata. Wiele innych procesów pamięci w grze również odnosi się do cielesności. Szwaczka Marta, trudniąca się pozyskiwaniem zębów i innych materiałów ze zwłok, może - na naszą prośbę - „zajrzeć do „wnętrza”, czyli dokonać wiwisekcji Bezimiennego. Z korporalnej pamięci wnętrzności zostaje wydobyty zapomniany pierścień. Same zaś wnętrzności (których wszakże jak nieśmiertelny nie potrzebujemy) mogą zostać przerobione na filakterie, choć „[m] usisz przyznać bez bicia, że bez względu na to, ile wspaniałych przymiotów i innych dobrodziejstw kryje się w tych jelitach, widok własnych wnętrzności owiniętych wokół przegubu niby upiorna bransoleta, przyprawia cię o mdłości"29.

Zabieg prezentacji wspomnień poprzez tatuaże i inne modyfikacje cielesności sprawia, że dyskurs pamięci staje się nierozerwalnie związany z postacią bohatera, a tym samym bliższy samemu graczowi, który w tę postać się wciela. Warto tu również zauważyć, że możliwość ingerencji w ciało, podkreślenie somatycznej niekoherencji, tworzy postać wyraźnie post-modernistyczną. Jak zauważa Agata Dziuban, odwołująca się do myśli Scotta Lasha, „[w]spółczesna tożsamość z konieczności staje się więc nielinearna i otwarta, uzależniona od sytuacji, kontekstów czy zdarzeń, przypominając bardziej patchwork niż arras, na którym poszczególne doświadczenia układają się w powiązaną jedną nicią całość” ${ }^{30}$. Dyskurs pamięci, który w tym przypadku można nawet za Richardem Shustermanem nazwać pamięcią somatyczną ${ }^{31}$, staje się mechanizmem przystosowawczym „do życia w świecie, w którym brakuje stałych punktów odniesienia, a w ich miejsce pojawiają się doraźne i zmienne obrazy"32. O ile jednak taki stan poza grą może zostać skwantyfikowany jako element kondycji ponowoczesnej Lyotarda, w medium gry komputerowej interaktywny bricolage odgrywa dodatkową rolę - wspomniane wcześniej budowanie odczucia obecności. Wiążącą nicią w tym przypadku staje się narracja gry, podstawowe

29. Tomasz „Medivh” Kiedrowicz, Brasnolety, „Game Exe Portal Fantastyczny” <https://gexe. $\mathrm{pl} /$ planescape-torment/art/2560, bransolety> (1.04.2019).

30. Agata Dziuban, Gry z tożsamością: Tatuowanie ciała w indywidualizującym się społeczeństwie polskim, Wydawnictwo Naukowe Uniwersytetu Mikołaja Kopernika, Toruń 2013, s. 58.

31. Richard Shusterman, Thinking Through the Body: Essays in Somaesthetics, Cambridge University Press, Cambridge 2012.

32. Dziuban, Gry z tożsamością..., s. 59. 
założenia opowieści, niezmienne dla każdego gracza. Dzięki jednak temu, że poszczególne „sytuacje, konteksty i zdarzenia” są w dużym stopniu modyfikowalne, gracz zyskuje większą możliwość ingerencji w fabułę, stworzenie własnej opowieści z puli dostępnych elementów. A to z kolei pozwala odczuć, że świat gry, w którym funkcjonujemy, jest reaktywny i otwarty na ingerencję.

Świat poza ciałem bohatera również zostaje wpleciony w procesy pamięci. Wiele przedmiotów, które odnajdujemy w czasie naszych podróży, nie służy jedynie praktycznym celom tu i teraz, ale niesie ze sobą nawiązania do przeszłości uniwersum gry, lub przeszłości samego bohatera. Nieprzerwany Krąg Zerthimona stanowi swego rodzaju święte pismo jednej z postaci, która towarzyszy nam w podróży. Wchodząc w interakcję z przedmiotem (przedstawioną jako kolejne opcje dialogowe), poznamy Ścieżkę Zerthimona, gnostyczny system wierzeń, u którego bazy leży stwierdzenie: „Siła tkwi w poznaniu samego siebie. Nauczyłem się, że kiedy ktoś nie zna siebie, jest zgubiony. Staje się narzędziem w rękach innych"33. Sama fizyczna forma tekstu nawiązuje do idei bricolage czy tekstu ergodycznego:

Okrąg składa się z szeregu zazębiających się kół, które można rozłożyć w zależności od ścieżki wybranej przez czytelnika [...]. Powiada się, że niektórzy zerthowie spędzają wiele lat, studiując kombinacje kręgów w poszukiwaniu nowych znaczeń nauk Zerthimona ${ }^{34}$.

Ścieżka Zerthimona może być nawet traktowana jak para-tekst nawiązujący do samej gry. Osiągnięcie ostatniego „poziomu” poznania wymaga, by gracz zainwestował punkty rozwoju w cechy Wiedzy i Inteligencji. Bez tego Nieprzerwany Krąg Zerthimona staje się tylko jednym z wielu przedmiotów zagracających ekwipunek naszego towarzysza. Podobnie Planescape: Torment pozwala na pełne zrozumienie wszelkich zawiłości narracji i świata przedstawionego jedynie wtedy, gdy gracz poświęci czas na dogłębną eksplorację wielowątkowej fabuły.

Ostatnim procesem pamięci wykorzystanym w grze jest przedstawienie wspomnień i przeszłości bohatera jako poprzednich inkarnacji - Wcielenia Dobrego, Pragmatycznego i Paranoicznego. Bezimienny nie może umrzeć ostatecznie, ale każda „chwilowa” śmierć odbiera mu wspomnienia, pozwalając (lub zmuszając) do rozpoczęcia życia na nowo, tworząc nowe wcielenia, od niewiele znaczącego rzezimieszka po generała armii. W świecie przedstawionym gry pozostają ślady obecności wspomnień, od postaci, które miały kontakt z poprzednimi wcieleniami Bezimiennego, po zamknięty w dwunastościanie

33. Autor nieznany, Ścieżka Zerthimona, „Grimuar Sferowca” <http://grimuar.pl/planescapetorment/\%C5\%9Bcie\%C5\%BCka-zerthimona> (1.04.2019).

34. Autor nieznany, Unbroken Circle of Zerthimon, w „Torment Wiki” <https://torment. fandom.com/wiki/Unbroken_Circle_of_Zerthimon> (1.04.2019), (przeł. T.G.). 
pamiętnik, który Wcielenie Paranoiczne skonstruowało jako pułapkę na inne inkarnacje, jakoby kradnące jej ciało. Same tatuaże są efektem działania Wcielenia Pragmatycznego, które w ten sposób zostawiło kolejnym inkarnacjom wskazówki. Ten sposób przedstawienia wspomnień sprawia, że gracz zmuszony jest do ciągłego dialogu z przeszłością. Wspomnienia nie są jedynie tłem do wydarzeń w teraźniejszości, ale stanowią interaktywny proces, w którym gracz nie tyle rekonstruuje, ile konstruuje pamięć. Sama struktura tego konstruktu odbiega zaś od tradycyjnego pojęcia wspomnień jako zbioru faktów, sugerując raczej możliwość otwartej interpretacji, subiektywnego postrzegania, pamięci zawodnej i personalnej. Następuje tu podobny proces do tego, który Rybicka opisała w odniesieniu do przykładów współczesnej literatury pamięci: „erozja pamięci jest punktem wyjścia. Wyzwaniem dla domysłu, wyobraźni, fikcji, choć zarazem rekonstrukcji na podstawie źródeł"35. A to z kolei doskonale współgra z podstawowymi założeniami medium rozrywki interaktywnej, gdzie wszakże wyzwanie i rekonstrukcja jest wpisana w naturę medium.

Podkreślenie fizyczność zapisu wspomnień pociąga za sobą ciekawe konsekwencje zarówno w wymiarze narracji, jak i rozgrywki. Wirtualna fizyczność obiektów i postaci otaczających nas w Planescape: Torment, tworzy świat, w którym pamięć nie jest jedynie realizowana narzędziowo. Pamięć przestaje być tylko sposobem edycji tekstu, formą sjużetu, jak to było w poprzednio omówionych przykładach. Staje się tutaj ważnym elementem cybertekstu, tworzy jego strukturę w ten sam sposób, w jaki poszczególne hiperłącza tworzą strukturę hipertekstu. Pamięć jest widoczna, namacalna, interaktywna. Konieczność ciągłej interakcji z pamięcią podkreśla chaotyczną naturę jej procesów, wymagającą powtórzeń, z których każde niesie ze sobą możliwość wystąpienia błędu. Zwraca uwagę na subiektywny wybór wspomnień ważnych i nieważnych, selektywność, która jednocześnie organizuje pamięć i ją wypacza. W następstwie tego nasza podróż ścieżkami pamięci, a tym samym percepcja czasu, ewoluuje od liniowej formy prezentacji, do czasu-kłącza, do otwartej struktury pozwalającej na nieliniową eksplorację. Oczywiście można stwierdzić, że nadal funkcjonujemy w zaplanowanym schemacie narracyjnym. Jednakże tu z kolei możemy powrócić do wspomnianego wcześniej konceptu obecności, w którym tak dużą rolę odgrywa właśnie prezentacja, czyli struktura danej narracji.

Ważna jest tu również sama ilość kotwic pamięci oraz ich wielowymiarowość odwołująca się do materii opowieści. Poprzednie wcielenia Bezimiennego różniły się od siebie charakterem i usposobieniem - kształtowane przez różne środowiska, ewoluowały w różne indywidualności. Wieloświat osobowości przedstawiony

35. Elżbieta Rybicka, Miejsce, pamięć, literatura, w „Teksty Drugie” 2008, 1-2, Instytut Badań Literackich Polskiej Akademii Nauk, Warszawa 2008, s. 26. 
jest w formie mnogości artefaktów, od tatuaży począwszy, na konstrukcjach architektonicznych skończywszy. Tym sposobem zaprezentowana zostaje wizja ludzkiego umysłu, w której podkreślona jest właśnie nieliniowość, asynchroniczność, wspólne funkcjonowanie przeciwstawnych pojęć i subiektywne postrzeganie rzeczywistości. W efekcie następuje fuzja znaczeń - materia i postrzeganie materii, efekty psychologiczne i fizyczne, wyobraźnia i rzeczywistość łączą się w nowy system, w którym trudno rozróżnić składowe. Powstaje splątana i wieloczynnikowa struktura czasopamięci, w której nawet sprzeczne modele przeszłości funkcjonują niczym paralelne rzeczywistości.

\section{Pamięć rozproszona, pamięć totalna}

Struktury czasopamięci mogą rozwijać się do tego stopnia, że wykształcają specyficzne gatunki i formy pamięci, a nawet stają się bytem niemal niezależnym od źródła - swego rodzaju metapamięcią. Jak zauważa Krzyżanowska, „[d]zieje się tak na poziomie nie tylko jednostkowym - naturę pamięci jednostkowej w jakiś sposób jest łatwiej doprecyzować - ale także na poziomie wspólnotowym" ${ }^{\text {"36 }}$. Warto więc przyjrzeć się jak w rozrywce interaktywnej tworzony jest ten typ pamięci. Tutaj jednak trzeba od razu podkreślić dwie sfery, w których kształtuje się metapamięć - świat przedstawiony gry oraz świat gracza, w którym narracja jest tworzona, lub raczej przetwarzana przez społeczność skoncentrowaną wokół danego tekstu.

W pierwszym przypadku jednostkowy bohater funkcjonuje wewnątrz gry w obrębie danej zbiorowości społecznej czy historycznej, która wszakże powinna posiadać jakąś formę pamięci. Jeśli ta osnowa fabularna nie ma natychmiastowego odniesienia do mechanik gry, jest najczęściej określana jak „lore”37. Występuje w formie bestiariuszy, książek i tekstów, które można odnaleźć w grze, jak również postaci, które stanowią żywe encyklopedie świata przedstawionego. W większości przypadków jednak ta wiedza jest traktowana głównie jako dodatkowy koloryt całej rozrywki, najczęściej tylko powierzchownie związany z meritum. Jeśli spojrzymy na to z perspektywy teorii rozrywki interaktywnej, teksty tego typu nie posiadają statusu tekstów ergodycznych, a interakcja z nimi sprowadza się jedynie do pasywnego odczytania.

36. Natalia Krzyżanowska, Dyskursy (nie)pamięci w przestrzeni miasta, „Studia Socjologiczne” 2016, 1 (220), Instytut Filozofii i Socjologii Polskiej Akademii Nauk w Warszawie, Warszawa, s. 129.

37. Problematyka przetłumaczenia „lore” jako elementu rozrywki interaktywnej w pełni zasługuje na osobną analizę. W jej skład mogą (ale nie muszą) wchodzić tak odrębne elementy jak historia świata, fabuła, bestiariusze, postacie niezależne itd. Można ją określić jako summę wiedzy dotyczącej świata przedstawionego gry - by uniknąć jednak tak rozbudowanego określenia, postanowiłem pozostać przy nazwie angielskiej. 
Nie należy jednak uważać tych tekstów jako zbędnego balastu do samej rozgrywki. W wielu grach ten typ tradycyjnej pamięci jest wykorzystany, by nadać głębię przedstawionemu światu, uczynić jego istnienie po części odrębnym od spersonalizowanego postrzegania bohatera opowieści. W tym przypadku "lore” może być traktowany jako tło do bardziej interaktywnych procesów zachodzących w grach. Po drugie, dzięki wprowadzeniu statycznych baz danych wiedzy o świecie, autorzy mogą uniknąć kolejnych klisz narracyjnych amnezji czy przybysza z zewnątrz. Samo to można odczytywać jako ciekawą perspektywę na fenomen przynależności do danej grupy społecznej, wpisującą się w zmiany paradygmatu interpretacji pamięci zbiorowej. Jak pisze Sztop-Rutkowska: „Zjawisko pamięci zbiorowej przez długi czas, zwłaszcza w europejskiej socjologii było badane i analizowane przez pryzmat Durkheimowskiego, holistycznego patrzenia na zjawiska społeczne - nacisk kładziony był na kolektywny wymiar pamięci i na jej funkcje wobec społeczeństwa czy grupy jako całości. Interakcjonizm symboliczny, ze swoim skupieniem uwagi na jednostce i jej tożsamości, zmienił tę optykę i skierował uwagę badaczy na mechanizmy wiążące pamięć indywidualną z poziomem pamięci zbiorowej" ${ }^{38}$. W tym przypadku mechanizmem przynależności nie jest jedynie fizyczna obecność w danym środowisku czy specyfika rasy (fantastycznej lub nie), gatunku, klasy, ale raczej pewna mentalna geografia, umiejętności operowania w zbiorowości kulturowej czy dostęp do pamięci wspólnoty. Po trzecie, „lore” często jest efektem pragmatycznego podejścia do tekstu nowych mediów, a analiza jego metod produkcji mówi wiele o samej kulturze tworzenia tekstów cybernetycznych. Zarys „lore” jest tworzony na początku procesu projektowania gry, jako specyficzna kanwa dla narracji przedstawionej w danym produkcie. Na późniejszym etapie, gdy ster projektu jest przejęty przez programistów, grafików i projektantów, pisarze otrzymują wolne pole do popisu - o ile nie wchodzą w drogę pozostałym członkom zespołu. Często prowadzi to nawet do rozdźwięku pomiędzy tym, co przedstawia „lore”, a tym, na co pozwala mechanika. Ale czy taka właśnie interpretacja nie współgra z postmodernistyczną interpretacją pamięci? Pamięci ulotnej, pamięci często oderwanej i zaprzeczającej rzeczywistości, ale też pamięci ciągle poszukującej źródła i przynależności? Scott Lash i John Urry zauważają, że: „decentralizacja tożsamości [...] jest wzmocniona przez efekty mediów elektronicznych"39. Być może w niezamierzony sposób rozdźwięk między „lore” a mechaniką gry jest jedynie echem tego, co możemy zaobserwować poza medium gier komputerowych.

38. Katarzyna Sztop-Rutkowska, Cyberpamięć czyli o tym, o czym (nie)pamiętamy w Sieci. Analiza pamięci lokalnej - Białystok i Lublin, w: Zwrot cyfrowy w humanistyce, red. Andrzej Radomski, Radosław Bomba, E-naukowiec, Lublin 2013, s. 140.

39. ScottLash, John Urry, The End of Organized Capitalism, John Wiley \& Sons, Hoboken 2018, s. 297. 
Innym aspektem praktycznym jest przesunięcie nacisku narracji na źródła zewnętrzne, co pozwala graczowi na wybór metodologii "grania” - skupienie się wyłącznie na mechanice lub próba poznania świata w pełni. W procesie twórczym obserwowalnym w nowych mediach większy nacisk jest kładziony na tworzenie projektów otwartych, interaktywnych, oferujących spersonalizowane doświadczenia. Warto również wspomnieć tu o próbach organizowania „lore” jako franczyzy, gdzie gra stanowi jedynie jeden aspekt $w$ multimedialnym świecie. Pamięć $w$ tym wypadku staje się rozproszona w różnych mediach, nabierając specyficznych charakterystyk cechujących dany produkt medialny.

Częstym problemem z taką implementacją „lore” jest to, że funkcjonuje ona w pewnym oderwaniu od podstawowego doświadczenia gry. By wytłumaczyć dlaczego tak się dzieje, dobrze jest znów wrócić do omówionych na początku różnic pomiędzy immersją a obecnością. O ile nadanie głębi światu przedstawionemu poprzez wprowadzenie opisów, legend, historii można uznać za immersyjne, nie jest to równoznaczne ze stworzeniem środowiska, w którym gracz może poczuć swoją obecność. Brakuje tutaj drugiego punktu z listy McMahan, czyli działania, interakcji gracza z przedstawionym środowiskiem, wyjścia poza pasywny odczyt. Rozwiązania tego problemu są różnorakie, od prostych metod rekonstrukcji sposobów prezentowania „lore” po zabiegi, które zmieniają postrzeganie świata przedstawionego gry.

Interesującą z kilku względów metodę zastosowano w Tyranny (Obsidian Entertainment, 2016). W wielu poprzednich grach, gdzie rozbudowany świat przedstawiony posiadał głęboką historię, „lore” najczęściej był przedstawiany przez bohaterów niezależnych, głównie w dialogach lub monologach. Przez to podkreślany był często rozdźwięk pomiędzy tym, co powinien wiedzieć bohater gry funkcjonujący w danym świecie a gracz - stąd popularność linii dialogowych zaczynająca się od słów: „Jak dobrze wiesz...". I tu pojawiał się ciekawy problem charakterystyczny dla medium rozrywki interaktywnej. Im bardziej oryginalna wizja świata, im bardziej autor starał się unikać rozpoznawalnych schematów czy klisz, tym więcej trzeba było wyjaśnić poprzez pasywny przekaz informacji. Tyranny zasługuje na szczególną uwagę, ponieważ tutaj problem rozwiązany jest poprzez wykorzystanie atutów samego medium. Podczas dialogów, niektóre słowa klucze (takie jak choćby nazwy własne) funkcjonują jako hiperlinki do okienek informacyjnych wyjaśniających dany termin. Ten proces usprawnia przekaz informacji, lub raczej sprawia, że przekaz przechodzi od wyraźnej dychotomii pamięć gracza-pamięć bohatera do spersonalizowanego doświadczenia wspomnień jako integralnej, współdzielonej świadomości. Co ciekawe, twórcy Tyranny zdecydowali się podkreślić właśnie tę interpretację systemu. Głosy Nerata (jedna z postaci w grze) ma zdolność kolekcjonowania wspomnień i umysłów innych postaci. Kiedy prowadzimy z nim rozmowę, zwyczajowy metatekst zmienia się i zaczyna funkcjonować jako jeden z „głosów”. 
Tym samym zwykły proces interfejsu nie tylko usprawnia rozrywkę, ale zostaje wkomponowany w świat przedstawiony.

Innym tekstem, w którym rozproszenie pamięci ściśle wiąże się z mechanikami rozgrywki, jest seria gier Souls (FromSoftware, 2009-2018). Tym, co odróżnia te gry od innych, jest nacisk kładziony na fragmentaryczność i niekompletność wspomnień. Większość „lore” gry jest przekazywana przez krótkie opisy znalezionych przedmiotów i zaklęć, jak również architekturę miejsc, wygląd napotkanych postaci i pojedyncze linie dialogowe (z których niektóre pojawiają się dopiero, gdy gracz przechodzi grę po raz kolejny). W tym przypadku interakcja, czy tworzona przez nią obecność, nie jest związana poprzez narrację jako taką, ale przez sam wysiłek konieczny do skonstruowania spójnej wizji świata. Jest to proces zaskakująco trudny, między innymi paradoksalnie dlatego, że zagłębianie się w „lore” jest zupełnie niepotrzebne, by ukończyć grę. Przed graczem staje więc kolejny problem - konieczność zaangażowania się w tekst poza jego wymiar absolutnie pragmatyczny.

W ten sposób dochodzimy do drugiej sfery, gdzie kształtuje się metapamięć, a którą stanowi społeczność skoncentrowaną wokół danej gry. W niej poszczególne elementy „lore” są omawiane, konstruowane i dekonstruowane, poddawane krytyce, uznawane za odpowiednie bądź nieodpowiednie. Jak zauważa Kain, „lore” w serii gier Souls,

[j]est nieprzenikniona, cudowna i być może inspiruje ciekawość i rodzaj eksploracji historii, której żadna inna gra naprawdę nie posiada. [...] trudno jest nie tyle znaleźć odpowiedzi, ile nawet zadać właściwe pytania, jeśli od czasu do czasu nie zagłębiasz się w rozważania dotyczące gry na YouTube'ie, forach gry lub wiki ${ }^{40}$.

Co ciekawe, ten rodzaj interakcji z narracją gry jest tworzony w głównej mierze przez graczy - rzadko dochodzi tu do ingerencji twórców w to, jaki ostateczny kształt przyjmie metapamięć. W grach, w których twórcy decydują się napisać (nadpisać?) istniejące formy poprzez określenie kanonu, niekiedy gracze przeciwstawiają temu swoją własną wersję wydarzeń (tak zwany „headcanon”).

\section{Pamięé, czass, obecność}

Jak zauważa Rybicka, pamięć jest „[z]arówno motywacją i budulcem architektoniki rzeczywistości przedstawionej (czyli konceptem literaturoznawczym), jak i kategorią egzystencjalną warunkującą tożsamość indywidualną oraz bycie

40. Erik Kain, The Wonderful Archeology of 'Dark Souls' Lore, „Forbes”, Dec. 12, 2012, $<$ https://www.forbes.com/sites/erikkain/2012/12/12/the-wonderful-archeology-of-dark-soulslore/\#71edddef7346> (1.04.2019), (przeł. T.G.). 
w świecie (więc pojęciem ze słownika antropologicznego), a wreszcie medium przeszłości i nośnikiem pamięci zbiorowej (w perspektywie socjokulturowej)"31. W rozrywce interaktywnej wszystkie powyższe formy pamięci funkcjonują na podobnych płaszczyznach. Niepamięć i pamięć utracona motywuje gracza do odnalezienia fragmentów własnej przeszłości, lecz ten proces w niektórych przypadkach wychodzi poza odtwórczą rekonstrukcję i staje się fundamentem do budowy nowego spojrzenia na świat przedstawiony. Sama budowa nie jest więc wyłącznie rekolekcją, ale staje się formą analizy teraźniejszości przez pryzmat przeszłych doświadczeń. Zamiast doświadczać procesów archeologii, gdzie pamięć przedmiotów traktowana jest jako statyczny znak minionego czasu, gracz bierze udział w recyklingu wspomnień, gdzie refren przeszłości powtarza się wielokrotnie, ale z każdą iteracją nabiera nowych znaczeń, nowych interpretacji. Taki świat przedstawiony staje się mniej rzeczywistością twórców gry, a bardziej rzeczywistością gracza.

Pamięć w rozrywce interaktywnej jest medium przeszłości i może funkcjonować jako pamięć zbiorowa. Tutaj jednakże po raz kolejny podkreślona jest jej interaktywna natura, zaproszenie do modyfikacji, remiksu, twórczego zapomnienia, wymazania, glitchu. To z kolei pozwala nam na nowo spojrzeć na funkcjonowanie pamięci w innych mediach, gdzie te procesy również istnieją, ale są mniej dostrzegalne, a nawet traktowane jako antyteza do roli pamięci w społeczeństwach.

Deleuze stwierdza: „Jeśli przeszłość współistnieje ze swoją własną teraźniejszością i jeśli współistnieje z sobą samą na różnych poziomach zacieśnienia, to musimy uznać, że sama teraźniejszość jest tylko najbardziej zacieśnionym, najbardziej skurczonym poziomem przeszłości” ${ }^{\text {"42 }}$. Jako kategoria egzystencjalna warunkująca tożsamość, pamięć wiąże przeszłość, teraźniejszość i przyszłość w linie przyczynowo-skutkowe. Ta interpretacja pamięci może być problematyczna dla rozrywki interaktywnej. Jest to wszakże medium podkreślające moment aktywności, natychmiastową ciągłość przyczyny i skutku, akcję i reakcję. Wypadkową tego procesu jest tożsamość, która wyraźnie funkcjonuje w teraźniejszości, ale jest często pozbawiona zakotwiczenia w świecie przedstawionym - gracz otrzymuje wrażenie bycia gościem, bardziej niż mieszkańcem rzeczywistości gry. I tutaj właśnie leży największe wyzwanie, tutaj otwierają się największe możliwości dla medium gier. Naturą tego medium jest interakcja, ale jedynie taka, której cel wychodzi ponad wprawianie mechanizmu gry w ruch. Tym celem jest stworzenie poczucia obecności, przynależności do świata przestawionego, empatii

41. Rybicka, Miejsce, pamięć..., s. 23.

42. Gilles Deleuze, Bergsonizm, przeł. Piotr Mrówczyński, Warszawa 1999, s. 74, cyt. za: Anna Boncela, Afirmacja Bergsona, „Sztuka i Filozofia” 18, Wydawnictwo Naukowe Semper, Warszawa 2000, s. 179. 
w stosunku do wydarzeń i postaci. Pamięć i niepamięć to narzędzia, które mogą $\mathrm{w}$ dużym stopniu pomóc $\mathrm{w}$ ukształtowaniu tego odczucia. Jednak ten proces jest znacznie bardziej efektywny, kiedy pamięć przestaje być niezmiennym i uświęconym monolitem, a staje się procesem twórczym, interaktywną siecią połączeń, bricolage'em stworzonym przez wielu autorów.

Taki sposób widzenia pamięci może z kolei prowadzić nas do pełniejszego poznania roli obecności w świecie rzeczywistym, jak też pomóc lepiej zrozumieć warunki funkcjonowania tożsamości narodowej, społecznej, kulturowej, klasowej. Nie sugeruję tutaj, że gry komputerowe pozwolą nam na przedefiniowanie powyższych pojęć, ale warto podkreślić ich rolę jako narzędzia edukacyjnego i poznawczego. Być może Nieprzerwany Krąg Zerthimona może odegrać pewną rolę w kształtowaniu świadomości otwartej na inne kultury i sposoby rozumowania? Może bricolage ciała i wspomnień Bezimiennego pozwoli dostrzec części składowe naszej osobowości? Może fragmentaryczny „lore” serii Souls pozwala zrozumieć, że pamięć to nie tylko kumulacja obiektów, lecz także umiejętność operowania nimi, wyjście poza ich rolę użytkową i zwrócenia uwagę na ideologie, które ucieleśniają? Pamięć w rozrywce interaktywnej jest zasobem ograniczonym, który jeśli zostanie umiejętnie wykorzystany, daje niemal nieograniczone możliwości narracyjne, światotwórcze i krytyczne. 